\title{
Clinical significance of monocyte heterogeneity
}

\author{
Brian K Stansfield ${ }^{1,2,6^{*}}$ and David A Ingram ${ }^{3,4,5}$
}

\begin{abstract}
Monocytes are primitive hematopoietic cells that primarily arise from the bone marrow, circulate in the peripheral blood and give rise to differentiated macrophages. Over the past two decades, considerable attention to monocyte diversity and macrophage polarization has provided contextual clues into the role of myelomonocytic derivatives in human disease. Until recently, human monocytes were subdivided based on expression of the surface marker CD16. "Classical" monocytes express surface markers denoted as CD14 ${ }^{++} \mathrm{CD} 16^{-}$and account for greater than $70 \%$ of total monocyte count, while "non-classical" monocytes express the CD16 antigen with low CD14 expression $\left(\mathrm{CD} 14^{+} \mathrm{CD} 16^{++}\right)$. However, recognition of an intermediate population identified as $\mathrm{CD} 14^{++} \mathrm{CD} 16^{+}$supports the new paradigm that monocytes are a true heterogeneous population and careful identification of specific subpopulations is necessary for understanding monocyte function in human disease. Comparative studies of monocytes in mice have yielded more dichotomous results based on expression of the Ly6C antigen. In this review, we will discuss the use of monocyte subpopulations as biomarkers of human disease and summarize correlative studies in mice that may yield significant insight into the contribution of each subset to disease pathogenesis.
\end{abstract}

Keywords: Monocyte; CD14; CD16; Ly6C; Macrophage; Cardiovascular; Atherosclerosis; Autoimmune Disease; Human; Mouse

\section{Introduction}

Until the late 1980s, monocytes were considered to represent a single population of circulating hematopoietic cells derived from the common myeloid progenitor cell in the bone marrow. The seminal work of Passlik et al. demonstrated that distinct monocyte subsets could be identified based on the expression of the surface antigen CD16 [1]. "Classical" monocytes do not express the CD16 antigen $\left(\mathrm{CD} 14^{++} \mathrm{CD} 16^{-}\right)$, while "non-classical" monocytes are smaller in size and express CD16 on the cell surface $\left(\mathrm{CD} 14^{+} \mathrm{CD} 16^{++}\right)$[1]. The expression pattern of the two surface markers lends some insight into their function. CD14 acts as a co-receptor for toll-like receptor 4 and mediates lipopolysaccharide (LPS) signaling, while the CD16 antigen is identified as FcyRIIIa and participates in innate immunity $[2,3]$. The subsequent two decades have yielded considerable insight into the role of each cell population in human disease; however, the recent emergence of an intermediate monocyte population denoted as $\mathrm{CD} 14^{++} \mathrm{CD} 16^{+}$ has shifted focus away from this simple classification system

\footnotetext{
*Correspondence: BSTANSFIELD@gru.edu

'Department of Pediatrics and Neonatal-Perinatal Medicine, Georgia Regents University, Augusta, Georgia

${ }^{2}$ Vascular Biology Center, Georgia Regents University, Augusta, Georgia

Full list of author information is available at the end of the article
}

[4-8] (Figure 1). As of 2010, three distinct monocyte populations outlined by Ziegler-Heitbrock et al. are officially recognized: $\mathrm{CD} 14^{++} \mathrm{CD} 16^{-}$(classical), $\mathrm{CD} 14^{++} \mathrm{CD} 16^{+}$(intermediate), and $\mathrm{CD}_{14} 4^{+} \mathrm{CD} 16^{++}$(non-classical) [4]. We will adhere to the official nomenclature for this review article.

Classical monocytes represent the largest population of monocytes and are important scavenger cells [4]. Nonclassical monocytes were often referred to as proinflammatory, secondary to their mobilization in disease and secretion of important inflammatory cytokines [7,9-11] (i.e. TNF- $\alpha$ ). The new tripartite view of monocyte subpopulations has shifted attention from the inflammatory characteristics of non-classical monocytes and supports a more significant role for intermediate monocytes in inflammation. Further, unique functions in angiogenesis, production of reactive oxygen species, and patrolling behavior have been attributed to $\mathrm{CD}_{16}{ }^{+}$monocytes [12-18]. In the present review, we will summarize the contribution of monocyte heterogeneity in human disease and draw across multiple common pathologies to characterize each monocyte subtype for clinical relevance. We will focus on the impact of monocytes in cardiovascular disease, including myocardial infarction, atherosclerosis, and stroke, chronic kidney disease, and autoimmune disease. Finally, we will 


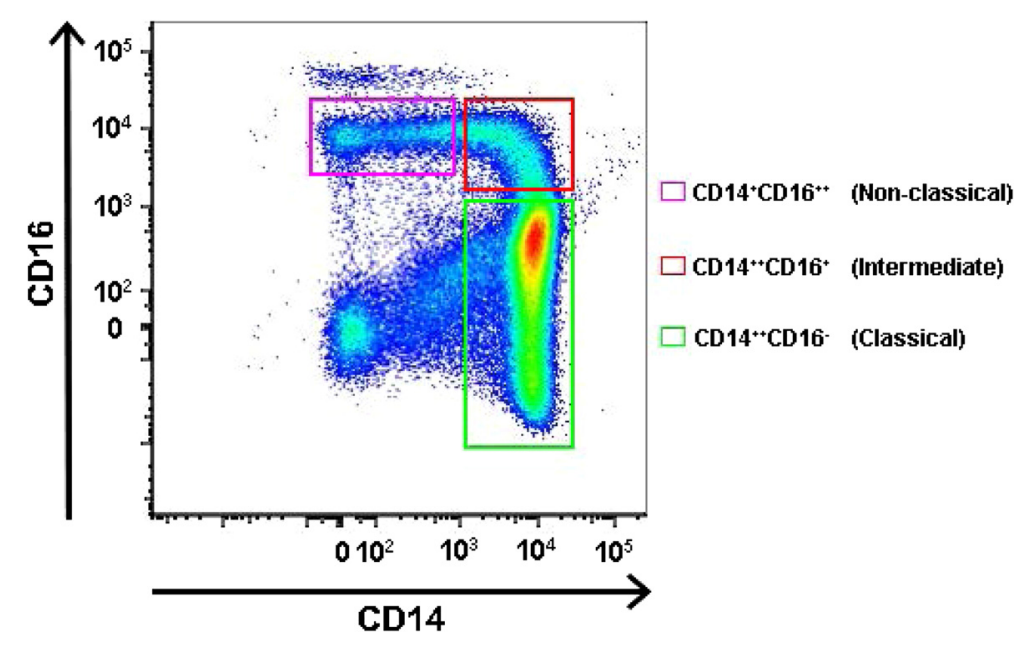

Figure 1 Sample gating strategy showing three human monocyte populations based on expression of CD14 and CD16. Relative expression of CD14 (x-axis) and CD16 (y-axis) is demonstrated on log scale. Classical monocytes (CD14 ${ }^{++}$CD16 $)$are gated in the green box, intermediate monocytes $\left(\mathrm{CD} 14^{++} \mathrm{CD} 16^{+}\right)$in the red box, and non-classical monocytes $\left(\mathrm{CD} 14^{+} \mathrm{CD} 16^{++}\right)$in the lavender box.

identify distinct murine monocyte populations and link their function in preclinical animal models to human monocyte function.

\section{Review}

\section{Monocyte ontogeny and heterogeneity}

Genetic profiles, antigen expression, and cytokine production of each monocyte population provide a foundation for hierarchical clustering and classification. Cros et al. showed that $\mathrm{CD} 14^{+} \mathrm{CD} 16^{++}$monocytes (non-classical) are segregated independently from intermediate and classical monocytes based on principal component analysis [14]. Functionally, $\mathrm{CD} 14^{++} \mathrm{CD} 16^{-}$and $\mathrm{CD} 14^{++} \mathrm{CD} 16^{+}$monocytes are more phagocytic than non-classical monocyte [14]. Conversely, other investigators have provided genetic and functional evidence to suggest that $\mathrm{CD}^{+} 6^{+}$monocytes cluster together and are more distinct from classical $\mathrm{CD}^{-} 6^{-}$monocytes $[7,16,19-21]$. Wong et al. showed significantly different genetic profiles between intermediate and classical monocytes, which supported independent findings in humans and rhesus monkeys [13,19,22]. Interestingly, cytokine production in response to LPS in vitro reveals a more complex relationship. Intermediate monocytes produced significantly more tumor necrosis factor- $\alpha$ (TNF- $\alpha)$ and interleukin- $1 \beta$ (IL-1 $\beta$ ) compared to the other populations; however, production of interleukins 6,8 , and 10 were approximate in intermediate and classical monocytes when compared to non-classical monocytes $[14,19]$.

Despite this controversy, stereotypic functions of classical and non-classical monocytes are beginning to emerge. CD14 is a pattern recognition receptor and classical monocytes are critical components of innate immunity, while $\mathrm{CD}^{+} 6^{+}$(intermediate and non-classical) monocytes are preferentially mobilized during inflammation and lend to their designation as "pro-inflammatory" [16,23,24]. The significant functional overlap of intermediate monocytes with classical and non-classical monocytes lends credence to the present hypothesis that $\mathrm{CD} 14^{++} \mathrm{CD} 16^{-}$monocytes arise from the bone marrow and give rise to $\mathrm{CD} 14^{++} \mathrm{CD} 16^{+}$and $\mathrm{CD} 14^{+} \mathrm{CD} 16^{++}$monocytes $[4,13,24]$. CD14 ${ }^{++} \mathrm{CD} 16^{-}$monocytes primarily produce monocyte chemotactic protein-1 (MCP-1/CCL2) and express its cognate receptor CCR2, as do intermediate monocytes $[14,22]$. CCR2 is critical for monocyte emigration from the bone marrow and monocyte homing [25-29]. Likewise, CD62L (SELL), expressed on classical monocytes, is an important early marker of progenitor cell commitment to specific progeny [30,31]. Population specific genetic profiles reveal a progressive increase in genes associated with maturation in intermediate and nonclassical monocytes when compared with classical monocytes $[19,24]$. Finally, in response to macrophage colony stimulating factor (M-CSF), intermediate monocytes are initially expanded in the peripheral blood followed by a delayed increase in non-classical monocyte frequency [24,32,33]. Though not dogmatic, general recognition that classical monocytes arise from the bone marrow and give rise to intermediate and non-classical monocytes has provided a platform for understanding monocyte maturation and methods of replenishment in disease states. Table 1 outlines the expression of surface markers for classical, intermediate, and non-classical monocytes.

Presently, murine monocytes are evenly distributed by their relative expression of the Ly6C antigen and are, for the most part, functionally distinct [34-39]. Ly6C $C^{\text {high }}$ monocytes co-express CCR2 and CD62L with low expression of the fractalkine receptor $\mathrm{CX}_{3} \mathrm{CR} 1$, whereas Ly6 ${ }^{\text {low }}$ monocytes have elevated expression of $\mathrm{CX}_{3} \mathrm{CR} 1$ with lower expression of CCR2 [39,40]. This expression 
Table 1 Profile of human and mouse monocyte subpopulations

\begin{tabular}{|c|c|c|c|c|c|}
\hline & \multicolumn{3}{|l|}{ Human } & \multicolumn{2}{|l|}{ Mouse } \\
\hline & $\mathrm{CD}_{14}{ }^{++} \mathrm{CD} 16^{-}$ & $\mathrm{CD}_{14}{ }^{++} \mathrm{CD} 16^{+}$ & $\mathrm{CD}_{14}{ }^{+} \mathrm{CD} 16^{++}$ & Ly6C ${ }^{\text {high }}$ & Ly6C ${ }^{\text {low }}$ \\
\hline CCR2 $2^{a, b, c}$ & ++ & + & - & ++ & + \\
\hline$C X_{3} C R 1^{a, b, c}$ & + & ++ & +++ & + & ++ \\
\hline $\mathrm{CD} 62 \mathrm{~L}^{\mathrm{a}, \mathrm{c}}$ & ++ & $+/-$ & - & ++ & - \\
\hline $\mathrm{CXCR}^{\mathrm{a}, \mathrm{c}}$ & ++ & $+/-$ & - & ND & ND \\
\hline CXCR2 ${ }^{\mathrm{a}, \mathrm{c}}$ & ++ & $+/-$ & - & ND & ND \\
\hline PSGL-1 ${ }^{d}$ & ++ & + & + & ++ & + \\
\hline CD11 $a^{e, f}$ & + & + & ++ & + & ++ \\
\hline CCR5 $5^{a, b, c}$ & + & ++ & - & + & + \\
\hline ACE $^{9}$ & + & ++ & + & ND & ND \\
\hline HLA-DR ${ }^{a}$ & - & ++ & + & ND & ND \\
\hline$C D 11 b^{a}$ & + & + & $+/-$ & + & + \\
\hline$C D 11 c^{e, h, i}$ & - & + & + & - & + \\
\hline $\mathrm{CD}_{4}{ }^{\mathrm{f}}$ & - & + & ++ & + & ++ \\
\hline$M H C \|^{a, e, h}$ & + & ++ & + & - & + \\
\hline
\end{tabular}

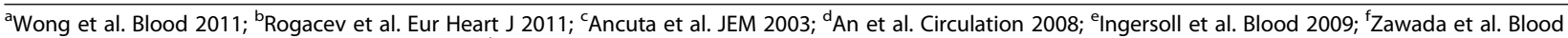

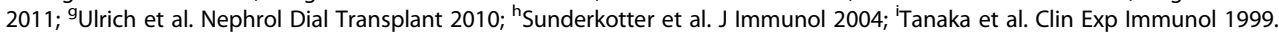

pattern supports the present view that Ly6 $\mathrm{C}^{\text {high }}$ monocytes are closely related to human classical $\left(\mathrm{CD} 14^{++} \mathrm{CD} 16^{-}\right)$ monocytes and conversely, Ly6C ${ }^{\text {low }}$ monocytes are analogous to the non-classical $\mathrm{CD} 14^{+} \mathrm{CD} 16^{++}$population $[14,19,24,40,41]$. Bone marrow cells are enriched for the Ly6C antigen and Ly6C $C^{\text {high }}$ monocytes are capable of giving rise to Ly6 $\mathrm{C}^{\text {low }}$ monocytes and other derivatives in some animal models [35,42-46]. However, Ly6C ${ }^{\text {high }}$ monocytes are preferentially recruited in inflammation and are the major source of cytokines such as TNF- $\alpha$ and IL-1 $\beta$ $[36,37,40]$. This departure from the functional description of classical human monocytes requires resolution and may be a function of current analytical techniques. For example, separation techniques leverage the expression of human monocyte markers to label each monocyte with differentially expressing antibodies. The binding of these labeling antibodies to poorly expressed surface antigens may preclude their activation and underestimate cytokine production and their response to various stimuli including LPS [16]. Additionally, expression patterns of classic markers for human monocytes (CD14, CD16, CD86, etc.) and murine markers (Ly6C, CCR2, CX3CR1) are not directly analogous between species. CCR2, for example, is preferentially expressed on Ly6 $\mathrm{C}^{\text {high }}$ murine monocytes and has provided evidence for their functional similarity to classical human monocytes. However, CCR2 is expressed on Ly6 $\mathrm{C}^{\mathrm{low}}$ monocytes as well, but is poorly expressed on human $\mathrm{CD} 16^{+}$ monocytes [41]. Further, these simple murine monocyte profiles (inflammatory vs. pro-inflammatory) likely limit our ability to understand individual murine monocyte function and hinder translation to human studies. Ingersoll et al. compared human CD16- and CD16+ monocytes with their murine counterpart to show that multiple proinflammatory and phagocytic antigens (TREM-1, CD64 and CD36) were highly expressed on Ly6C ${ }^{\text {low }}$ monocytes and approximated relative expression in CD16- human monocytes [41]. However, antigen expression patterns and genomic data mostly confirm the present grouping of Ly6 $\mathrm{C}^{\text {high }}$ monocytes with $\mathrm{CD}_{1} 4^{++} \mathrm{CD} 16^{-}$human monocytes $[14,40,41]$. Several recent reviews attempt to resolve this controversy $[24,39,40]$.

\section{Monocytes phenotypes in cardiovascular disease}

Expansive remodeling and leukocyte infiltration of the left ventricle in response to coronary artery occlusion is predictive of poor outcomes [40,47]. Monocyte mobilization during the evolving infarction and recovery period follow a sequential pattern. Tsujioka et al. studied the mobilization of $\mathrm{CD}_{16}{ }^{-}$and $\mathrm{CD} 16^{+}$monocytes during the natural progression of acute myocardial infarction (AMI) in a Japanese patient population [48]. Circulating $\mathrm{CD}_{16}{ }^{+}$monocytes were diminished in patients diagnosed with AMI at the time of admission and rose significantly over the first week after diagnosis. The mobilization of $\mathrm{CD}_{16}{ }^{+}$monocytes was preceded by increased $\mathrm{CD} 14^{++} \mathrm{CD} 16^{-}$monocytes in the first days following AMI admission. Circulating monocyte populations did not differ between groups; however, peak levels of $\mathrm{CD} 14^{++} \mathrm{CD} 16^{-}$monocytes were a negative predictor of myocardial salvage and no relationship between $\mathrm{CD}_{16}{ }^{+}$monocytes and infarction size was noted in this study [48]. Other human studies and murine models of myocardial infarction support these findings [50-53]. Ly6 $C^{\text {high }}$ monocytes, corresponding to classical 
human monocytes, accumulate in the myocardium immediately after AMI and are followed by a recovery period denoted by expansion of Ly6C ${ }^{\text {low }}$ monocytes (analogous to human non-classical monocytes) [50,54]. However, characterization of human monocyte mobilization in Tsujioka et al. is difficult to interpret, as $\mathrm{CD} 16^{+}$monocytes were not distinguished into intermediate and non-classical populations [48]. Recently, monocyte subtypes were analyzed in a cohort of patients admitted for AMI and compared to patients with stable coronary artery disease (CAD) and a second cohort of healthy controls [55]. Patients admitted for AMI had a 60-80\% increase in total monocyte count and a disproportionate increase (3-fold) in intermediate $\left(\mathrm{CD} 14^{++} \mathrm{CD} 16^{+}\right)$monocytes when compared with patients admitted with CAD and healthy controls. The intermediate monocyte population remained elevated for the subsequent 7 days after AMI and trended to background control levels by day 30 . The authors go on to show that return of the intermediate monocyte population to normal frequency correlated with decreased troponin levels and return of left ventricular ejection fraction [55]. These smaller cohort studies are supported by a large prospective cohort study of persons undergoing angiography. Intermediate monocyte frequency strongly correlated with a composite outcome of cardiovascular death, non-fatal AMI, and non-hemorrhagic stroke in 951 patients. A planned secondary analysis revealed that patients with the highest frequency of intermediate monocytes had a $40 \%$ risk of experiencing a cardiovascular event within three years of study enrollment [49]. Collectively, clinical studies suggest an intriguing role for monocyte differentiation as a diagnostic and predictive biomarker in patients suffering AMI.

Similar to the findings observed in patients suffering AMI, a characterization study of human monocyte mobilization in the days following a stroke revealed an expansion of intermediate monocytes by day 2 , while the classical monocyte population was unperturbed [56]. Non-classical $\mathrm{CD} 14^{+} \mathrm{CD} 16^{++}$monocyte frequency inversely mirrored intermediate monocyte frequency and reached the nadir by day 2 after stroke. The classical monocyte population was lower at the time of admission for stroke in surviving patients and correlated with improved prognosis. Intermediate monocyte mobilization over the subsequent 48 hours following stroke also correlated with stroke severity and increased mortality rates, which held significance following adjustment for age and stroke severity scoring [56,57]. A second cohort of 36 stroke patients supported the increased frequency of intermediate monocytes in the peripheral blood in the days to weeks following infarction; however, Kaito et al. showed that classical monocyte numbers increased immediately following presentation for stroke [58]. A positive correlation with stroke severity score in this study was also observed and may be explained by a strong association with progressing infarction [58]. Thus, assessment of monocyte subsets following admission for stroke may show a timedependent predictive value in outcomes and survival.

\section{Monocytes in chronic cardiovascular inflammation}

Atherosclerosis is the result of complex interactions between circulating leukocytes and the vascular wall, which are likely propagated by chronic secretion of growth factors and inflammatory cytokines. The lack of true homology between murine and human monocyte subpopulations limit the direct application of findings in murine atheroma to that observed in human cohorts. Ly6 $\mathrm{C}^{\text {high }}$ monocytes, the murine correlate of human classical monocytes, drive atherosclerosis in transgenic animal models based on the genetic deletion of apolipoprotein $\mathrm{E}$ or the LDL receptor [26,37,45,59-61]. Ly6C $C^{\text {high }}$ monocytes preferentially bind to the activated endothelium in atherogenic ApoE knockout mice and infiltrate the developing atheroma to give rise to lesional macrophages and, eventually, foam cells [26,37]. Comparatively, $\mathrm{CD} 16^{+}$monocytes are primarily implicated in human atherosclerosis. Increased frequency of nonclassical monocytes, in association with other markers of dyslipidemia, has been demonstrated in multiple human studies $[24,62,63]$. Non-classical monocytes are mobilized in patients with hypercholesterolemia and their frequency in the peripheral blood appears to be directly correlated with total cholesterol and triglyceride level and inversely proportional to HDL concentration [62-64]. Recent work attempting to differentiate the contribution of CD16+ monocytes to atherosclerosis show that intermediate monocyte frequency is closely related to severity of angina and may contribute to atherosclerosis $[65,66]$. These findings have implications on therapeutic efficacy since monocyte subpopulations have variable expression of scavenger receptors that participate in cholesterol uptake and metabolism. For instance, an early randomized trial targeting hypercholesterolemia showed that statin treatment (fluvastatin) increased $\mathrm{CD}^{+} 6^{+}$monocytes [63]. Other studies have not identified a similar increase in non-classical monocytes following initiation of a statin (rosuvastatin, atorvastatin, and pivastatin), which may suggest class-dependent effects on monocyte frequency $[67,68]$.

To compound the difficulty of interpreting these studies, the vast majority of human studies failed to include the intermediate monocyte population in their analysis. Recently, intermediate monocyte frequency was identified as a positive predictor of major cardiovascular event in two large European cohorts of 438 and 951 patients [49,69]. Further, intermediate monocyte frequency negatively correlated with HDL and Apo-1 $[49,69]$, which is likely consistent with previous clinical studies demonstrating an association between $\mathrm{CD} 6^{+}$monocytes and markers of dyslipidemia. These findings are particularly intriguing since intermediate monocytes may possess significant inflammatory properties and 
exaggerate oxidative stress when compared with nonclassical monocytes. Intermediate monocytes express CCR2 and CCR5, which are critical for monocyte homing and trans-endothelial migration into the atherosclerotic plaque $[26,27,61,70]$. Genetic deletion of CCR2 or CCR5 in ApoE knockout mice significantly reduces atherosclerosis and monocyte mobilization [71-75]. Further exploration of the relationship between intermediate $\left(\mathrm{CD} 14^{++} \mathrm{CD} 16^{+}\right)$monocytes and atherosclerosis will significantly advance our understanding of pro-atherogenic conditions and aide in the design of novel cell-directed therapies for the treatment of atherosclerosis.

Obesity represents a chronic inflammatory state that increases the risk for heart disease and stroke by greater than fifty percent $[76,77]$. Several groups have independently demonstrated that the frequency of nonclassical and intermediate monocytes positively correlates with WHO obesity classification and fat mass [24,64,78-80]. In fact, a cohort of 105 subjects with WHO class II and III obesity had an increased frequency of non-classical and intermediate monocytes in the peripheral blood compared to healthy controls; a finding that was not observed in WHO class I subjects [64]. A modest 5\% reduction in fat mass significantly reduced non-classical monocyte frequency and improved glycemic control in obese diabetic patients [64]. Not surprisingly, the vast majority of positive correlative studies between non-classical monocyte frequency and cardiovascular disease loose statistical significance in post-hoc analysis correcting for BMI. These epidemiologic observations in human cohorts provide evidence for a direct link between adiposity, inflammation, and monocyte maturation.

Animal models of metabolic disease may provide some clues to the connection between obesity and vascular inflammation. ApoE knockout $\left(\mathrm{ApoE}^{-/-}\right)$mice provided a high fat western diet develop morbid obesity and have evidence of chronic inflammation. Loss of ApoE expression in hematopoietic cells appears to drive monocyte proliferation, mobilization, and differentiation in the development of atherosclerosis [81]. $\mathrm{ApoE}^{-/-}$mice on high fat diet (HFD) developed a time-dependent exponential increase in Ly6 $\mathrm{C}^{\text {high }}$ monocyte frequency in the peripheral blood and spleen compared to wildtype mice on HFD [37]. Ly6C $C^{\text {high }}$ monocytes rapidly incorporated into the developing atheroma and accounted for the vast majority of lesional macrophages $[37,45]$. However, local macrophage turnover within atheroma may drive foam cell formation independent of monocyte recruitment [36]. Several studies have demonstrated that ApoE interacts with the ATP-binding cassette transporters (i.e. ABCA1) to coordinate cholesterol efflux and monocyte recruitment [81-83]. Loss of ABCA1, and other cholesterol transport proteins, accelerates lesion formation and likely participates in myeloid cell proliferation and function.

Recent attention to the role of adventitial adipose tissue, termed perivascular adipose tissue or PVAT, provides a novel look at the relationship between adiposity and vascular inflammation. Perivascular adipocytes secrete growth factors and adipokines that stimulate an inflammatory response by recruiting monocytes and other leukocytes to the vascular wall [84-88]. Precursor and differentiated adipocytes accumulate near atheroma in the perivascular adventitia of conduit vessels and expand with obesity [86]. Monocyte chemotactic protein-1 (MCP-1/CCL2) is highly secreted by perivascular adipocytes and is a potent mitogen for circulating monocytes [85,89]. Genetic deletion of MCP-1 in mice impedes macrophage infiltration and lipid deposition following arterial injury [85]. Interestingly, MCP-1 is sequentially expressed in the adventitia followed by the media and intima after coronary artery injury, suggesting a central role for perivascular adipocytes in monocyte recruitment [90]. These data provide evidence that perivascular adiposity, along with visceral and subcutaneous fat, participate in vascular inflammation and monocyte chemotaxis. How perivascular adipocytes interact with circulating hematopoietic cells and isolating their effect on leukocyte recruitment from other fat stores in vascular inflammation are important future areas of investigation.

\section{Monocyte subpopulations in kidney disease}

Chronic kidney disease (CKD) is closely related with cardiovascular health and commonly exists as a co-morbid condition in persons with cardiovascular disease. Persons with CKD often suffer from atherosclerosis and are at increased risk for mortality following an acute cardiovascular event $[91,92]$. Patient cohorts have uniformly demonstrated that increased intermediate $\left(\mathrm{CD} 14^{++} \mathrm{CD} 16^{+}\right)$monocyte frequency is associated with cardiovascular event rate and increased mortality [70,78,93-95]. A study of 119 patients with CKD demonstrated an increased frequency of intermediate monocytes in the peripheral blood of hemodialysis-dependent CKD patients compared to CKD patients with adequate native renal function [70]. Depletion of intermediate monocytes during hemodialysis was associated with an increased cardiovascular event-free period and reduced mortality in patients with end-stage renal disease $[70,96]$. Classical and non-classical monocytes have failed to show a correlation with mortality in CKD patients regardless of the need for hemodialysis. Subgroup analysis identified intermediate monocytes expressing angiotensinconverting enzyme (ACE) were significantly higher in CKD patients with severe atherosclerosis and may yield additional prognostic value [94-96]. Increased ACE expression in intermediate monocytes has also been demonstrated in patients with abdominal aortic aneurysm and appeared to be independent of CKD classification [97]. While the role 
of ACE (CD143) on circulating monocytes remains unknown, the renin-angiotensin system is critical for monocyte maturation and function and targeting this signaling axis may be of therapeutic benefit in monocyte-driven human disease $[98,99]$. Along this line of inquiry, a small cohort of dialysis-dependent CKD patients was randomized to an angiotensin receptor 1 blocker (losartan) or other anti-hypertensive medication and monocyte populations were evaluated. The losartan group showed a reduction of $\mathrm{CD}_{16}{ }^{+}$monocytes in their peripheral blood after two months of therapy compared to patients receiving antihypertensive medication that did not target the reninangiotensin axis [100]. The authors demonstrate that the $\mathrm{CD} 16^{+}$monocytes produced TNF- $\alpha$ in vitro; however their gating strategy failed to distinguish intermediate and nonclassical monocytes within the $\mathrm{CD} 16^{+}$population. While $\mathrm{CD} 14^{++} \mathrm{CD} 16^{+}$monocytes appear to be an important biomarker of CKD severity, their role in the evolution of CKD is yet to be determined.

\section{Monocytes and autoimmune disease}

Monocyte-mediated inflammation has long been targeted in the treatment of rheumatoid arthritis. Attention to monocyte heterogeneity has expanded our understanding of rheumatologic diseases and provided new interventions for patients. Most groups have demonstrated an expansion of $\mathrm{CD}_{16} 6^{+}$monocytes in patients with rheumatoid arthritis with the recent delineation of $\mathrm{CD}_{16}{ }^{+}$subpopulations strongly suggesting that $\mathrm{CD} 14^{++} \mathrm{CD} 16^{+}$monocytes are the principle inflammatory effectors [21,101,102]. $\mathrm{CD}_{16}{ }^{+}$monocytes are found in the synovial fluid of RA patients and are associated with joint destruction [101]. Elevation of the $\mathrm{CD}_{16} 6^{+}$monocyte frequency in RA patients was recently demonstrated to be primarily an expansion of the intermediate population [21]. Sequestering the inflammatory properties of $\mathrm{CD} 14^{++} \mathrm{CD} 16^{+}$monocytes may inhibit joint injury and signify response to therapy. Monoclonal antibodies directed against TNF- $\alpha$ (Inflixamab, Adalimumab, Etanercept) have been extremely effective in the treatment of RA and may target, in part, intermediate and non-classical $\mathrm{CD} 16^{+}$monocytes. A comparison study of anti-TNF- $\alpha$ antibodies demonstrated a reduction in $\mathrm{CD} 14^{++} \mathrm{HLADR}^{+}$monocytes in RA patients taking infliximab that the authors suggest may account for the increased sepsis event rate noted in this study population [103]. HLADR is an important third marker (along with CD86) that is highly expressed on intermediate monocytes and less so on non-classical monocytes [104]. A larger cohort of RA patients (111 total) showed a slight, but non-significant increase in intermediate monocyte frequency in early RA that was profoundly increased in RA patients with long-standing disease [105]. In response to treatment with methotrexate, the authors identified that CD16 expression on CD14 ${ }^{++}$ monocytes was a negative predictor of response after 14 weeks of therapy. Both RA patients with and without a history of treatment with immune modulating agents showed a negative correlation between intermediate monocyte frequency during treatment and disease activity scores [105]. These clinical studies suggest that intermediate monocyte frequency may predict response to therapy and side effect profile in RA patients using immunosuppressive therapy. However, cytokine production has not been linked to monocyte subpopulation frequency in RA patients during active disease or following treatment. Therefore, the use of monocyte markers as a biomarker for therapeutic response remains limited.

Similar to RA patients, $\mathrm{CD}^{+} 6^{+}$monocytes are preferentially expanded in persons with both Crohn's Disease (CD) and ulcerative colitis $[11,106,107]$. Grip et al. showed a spike in intermediate monocyte frequency in $\mathrm{CD}$ patients with active disease, which was marked by increased expression of CCR2 on the intermediate monocyte population. Classical and intermediate monocytes expressed similar levels of CCR2 during active disease and the expression pattern of CCR2 on the intermediate monocyte population in $\mathrm{CD}$ patients was significantly elevated compared to the expression of CCR2 on matched healthy controls [11]. These findings are intriguing and suggest that monocytes, within a sub-classification system, may have alternative phenotypic signatures in response to inflammation. Further, this data supports the independent finding that MCP-1 (CCL2) levels are increased in patients with inflammatory bowel disease and correlate with disease severity $[108,109]$. Recently, Thiesen et al. showed enhanced migration of classical monocytes isolated from $C D$ patients in response to MCP-1 (CCL2) and increased CD14 expression in macrophages isolated from inflamed intestinal mucosa of CD patients [110]. The CD14 ${ }^{++}$HLADR $^{\text {low }}$ macrophages isolated from the colon of $\mathrm{CD}$ patients expressed high levels of CD62L which supports a classical monocyte origin, however, these macrophages also expressed the fractalkine receptor $\mathrm{CX}_{3} \mathrm{CR} 1$ which is more characteristic of nonclassical monocytes [110]. Other groups have found a more pronounced infiltration of $\mathrm{CD}^{+} 6^{+}$monocytes in actively inflamed tissue from $\mathrm{CD}$ patients that corresponded with increased staining for TNF- $\alpha$ [107]. Resolution between these findings may again point back to an integral role for intermediate monocytes in active $\mathrm{CD}$.

\section{Gaps and future directions in understanding monocyte heterogeneity}

Recent adherence to the tripartite description of monocytes based on expression of CD14 and CD16 along with standardized gating strategies has enabled investigators to more thoroughly explore the nature of monocyte differentiation and function in human disease. However, the recognition of an intermediate population that most truly represents an 
inflammatory monocyte casts a shadow on previous studies demonstrating expansion of classical and non-classical monocytes during inflammation. Thus, a re-examination of previous clinical studies and human cohorts with a uniform gating strategy and consistent use of approved nomenclature is warranted.

Though evidence of monocyte mobilization in human disease has now been demonstrated, the question of whether their rise is consequential of the illness/inflammation or directly contributes to the inflammatory process remains largely unanswered. In particular, does the increase in $\mathrm{CD}_{16} 6^{+}$monocyte (intermediate and non-classical) frequency observed in cases of both acute and chronic inflammation result from increased differentiation or do they arise independently in response to inflammatory signaling cascades. Human studies addressing these questions will likely focus on chronic diseases with periodic episodes of acute inflammation (i.e. autoimmunity), as several groups have pointed out that classical monocytes appear to exhibit a progressive increase in CD16 expression during acute illness $[107,111,112]$. A particularly interesting subset of these patients includes those with disease primarily affecting a single organ such as RA or Crohn's Disease. Comparative studies of monocyte frequency between the peripheral blood and diseased organ have generated promising data supporting the maturation of these monocytes in the peripheral blood prior to infiltration. Further, does the spleen function as a monocyte reservoir for mobilization during periods of acute inflammation as has been observed in mice [45]? Supportive in vitro characterization of all monocyte populations, especially the intermediate subset, will help define the inflammatory signature of each population and may lead to the designation of a true pro-inflammatory monocyte. Specific therapeutic targeting of the offending monocyte population may limit the need for treatments that indiscriminately target all monocytes and the important side effect profile associated with these types of therapies. Finally, could preferential recruitment of a less inflammatory monocyte population limit inflammation and promote healthy repair?

\section{Conclusions}

Recognition of three monocyte populations with diversified and heterogeneous responses in health and disease has increased mechanistic insight into the pathogenesis of inflammation as it relates to both chronic and acute illness. The more dichotomous murine monocyte populations, denoted as Ly6 $\mathrm{C}^{\text {high }}$ and Ly6C $\mathrm{C}^{\text {low }}$, hinder the ability to directly translate animal findings to humans. Careful mechanistic and lineage tracing studies in mice and humans will enhance our understanding of monocyte function in health and disease. At present, the intermediate monocyte population appears to represent an inflammatory monocyte population and therefore harnessing the inflammatory capacity of intermediate monocytes may promote a healthy response to injury or inflammation. Selective depletion of intermediate monocytes requires a highly specific surface marker regimen. Therefore, uniform adoption of the recommended gating strategies and nomenclature for proper identification of each monocyte subpopulation is necessary to provide a clear picture of their role in human disease $[4,5,24]$.

\section{Abbreviations}

ABCA1: ATP-binding cassette transporter-1; ACE: Angiotensin-converting enzyme; AMI: Acute myocardial infarction; Apo-1: Apolipoprotein-1; ApoE: Apolipoprotein-E; CAD: Coronary artery disease; CCR2: C-C motif receptor-2; CCR5: C-C motif receptor-5; CD: Crohn's disease; CD14: Cluster of differentiation 14; CD16: Cluster of differentiation 16; CD62L/SELL: Cluster of differentiation 62 L; CD86: Cluster of differentiation 86; CKD: Chronic kidney disease; $\mathrm{CX}_{3} \mathrm{CR} 1$ : Fractalkine receptor; HDL: High density lipoprotein; HFD: High fat diet; HLADR: Human leukocyte antigen-DR; IL-1ß: Interleukin-1 $\beta$; LDL: Low density lipoprotein receptor; LPS: Lipopolysaccharide; Ly6C: Lymphocyte antigen 6C; MCP-1/CCL2: Monocyte chemotactic protein-1/ chemokine (C-C Motif) ligand-2; M-CSF: Macrophage-colony stimulating factor; PVAT: Perivascular adipose tissue; RA: Rheumatoid arthritis; TNF-a: Tumor necrosis factor-a.

\section{Competing interests}

The authors have no conflicts of interest to resolve or competing interests to disclose.

\section{Authors' contribution}

BS and DI contributed equally to drafting, editing, and approving all aspects of this review.

\section{Acknowledgements}

The authors would like to thank Julie A. Mund for insightful comments and editing of Figure 1. This work was supported by NIH P50 NS052606 and GRU S00104.

\section{Author details}

${ }^{1}$ Department of Pediatrics and Neonatal-Perinatal Medicine, Georgia Regents University, Augusta, Georgia. Vascular Biology Center, Georgia Regents University, Augusta, Georgia. ${ }^{3}$ Herman B. Wells Center for Pediatric Research, Georgia Regents University, Augusta, Georgia. ${ }^{4}$ Department of Pediatrics and Neonatal-Perinatal Medicine, Indiana University School of Medicine, Indianapolis, Indiana, USA. ${ }^{5}$ Department of Biochemistry and Molecular Biology, Indiana University School of Medicine, 699 Riley Hospital Drive, RR208, Indianapolis, IN 46202, USA. ${ }^{6}$ Medical College of Georgia at Georgia Regents University, 1120 15th St, BIW-6033, Augusta, GA 30912, USA.

Received: 5 September 2014 Accepted: 29 October 2014

Published online: 14 February 2015

\section{References}

1. Passlick B, Flieger D, Ziegler-Heitbrock HW: Identification and characterization of a novel monocyte subpopulation in human peripheral blood. Blood 1989, 74:2527-2534

2. Clarkson SB, Ory PA: CD16. Developmentally regulated IgG Fc receptors on cultured human monocytes. J Exp Med 1988, 167:408-420.

3. Wright SD, Ramos RA, Tobias PS, Ulevitch RJ, Mathison JC: CD14, a receptor for complexes of lipopolysaccharide (LPS) and LPS binding protein. Science 1990, 249:1431-1433.

4. Ziegler-Heitbrock L, Ancuta P, Crowe S, Dalod M, Grau V, Hart DN, Leenen PJ, Liu YJ, MacPherson G, Randolph GJ, Scherberich J, Schmitz J, Shortman K, Sozzani S, Strobl H, Zembala M, Austyn JM, Lutz MB: Nomenclature of monocytes and dendritic cells in blood. Blood 2010, 116:e74-e80.

5. Heimbeck I, Hofer TP, Eder C, Wright AK, Frankenberger M, Marei A, Boghdadi G, Scherberich J, Ziegler-Heitbrock L: Standardized singleplatform assay for human monocyte subpopulations: lower CD14 + CD16++ monocytes in females. J Int Soc Anal Cytol 2010, 77:823-830.

6. Skrzeczynska-Moncznik J, Bzowska M, Loseke S, Grage-Griebenow E, Zembala M, Pryjma J: Peripheral blood CD14high CD16+ monocytes are main producers of IL-10. Scand J Immunol 2008, 67:152-159. 
7. Belge KU, Dayyani F, Horelt A, Siedlar M, Frankenberger M, Frankenberger B, Espevik T, Ziegler-Heitbrock L: The proinflammatory CD14 + CD16 + DR++ monocytes are a major source of TNF. J Immunol 2002, 168:3536-3542.

8. Ancuta P, Rao R, Moses A, Mehle A, Shaw SK, Luscinskas FW, Gabuzda D: Fractalkine preferentially mediates arrest and migration of CD16+ monocytes. J Exp Med 2003, 197:1701-1707.

9. Schlitt A, Heine GH, Blankenberg S, Espinola-Klein C, Dopheide JF, Bickel C, Lackner KJ, Iz M, Meyer J, Darius H, Rupprecht HJ: CD14 + CD16+ monocytes in coronary artery disease and their relationship to serum TNF-alpha levels. Thromb Haemost 2004, 92:419-424.

10. Fingerle G, Pforte A, Passlick B, Blumenstein M, Strobel M, Ziegler-Heitbrock HW: The novel subset of CD14+/CD16+ blood monocytes is expanded in sepsis patients. Blood 1993, 82:3170-3176.

11. Grip O, Bredberg A, Lindgren S, Henriksson G: Increased subpopulations of CD16(+) and CD56(+) blood monocytes in patients with active Crohn's disease. Inflamm Bowel Dis 2007, 13:566-572.

12. Mayer A, Hiebl B, Lendlein A, Jung F: Support of HUVEC proliferation by pro-angiogenic intermediate CD163+ monocytes/macrophages: a co-culture experiment. Clin Hemorheol Microcirc 2011, 49:423-430.

13. Zawada AM, Rogacev KS, Rotter B, Winter P, Marell RR, Fliser D, Heine GH: SuperSAGE evidence for CD14++CD16+ monocytes as a third monocyte subset. Blood 2011, 118:e50-e61.

14. Cros J, Cagnard N, Woollard K, Patey N, Zhang SY, Senechal B, Puel A, Biswas SK, Moshous D, Picard C, Jais JP, D'Cruz D, Casanova JL, Trouillet C, Geissmann F: Human CD14dim monocytes patrol and sense nucleic acids and viruses via TLR7 and TLR8 receptors. Immunity 2010, 33:375-386.

15. Randolph GJ, Sanchez-Schmitz G, Liebman RM, Schakel K: The CD16(+) (FcgammaRIII(+)) subset of human monocytes preferentially becomes migratory dendritic cells in a model tissue setting. J Exp Med 2002, 196:517-527.

16. Wong KL, Yeap WH, Tai JJ, Ong SM, Dang TM, Wong SC: The three human monocyte subsets: implications for health and disease. Immunol Res 2012, 53:41-57.

17. De Palma M, Murdoch C, Venneri MA, Naldini L, Lewis CE: Tie2-expressing monocytes: regulation of tumor angiogenesis and therapeutic implications. Trends Immunol 2007, 28:519-524.

18. Murdoch C, Tazzyman S, Webster S, Lewis CE: Expression of Tie-2 by human monocytes and their responses to angiopoietin-2. J Immunol 2007, 178:7405-7411.

19. Wong KL, Tai JJ, Wong WC, Han H, Sem X, Yeap WH, Kourilsky P, Wong SC: Gene expression profiling reveals the defining features of the classical, intermediate, and nonclassical human monocyte subsets. Blood 2011, 118:e16-e31.

20. Frankenberger M, Sternsdorf T, Pechumer H, Pforte A, Ziegler-Heitbrock HW: Differential cytokine expression in human blood monocyte subpopulations: a polymerase chain reaction analysis. Blood 1996, 87:373-377.

21. Rossol M, Kraus S, Pierer M, Baerwald C, Wagner U: The CD14(bright) CD16 + monocyte subset is expanded in rheumatoid arthritis and promotes expansion of the Th17 cell population. Arthritis Rheum 2012, 64:671-677.

22. Kim WK, Sun Y, Do H, Autissier P, Halpern EF, Piatak M Jr, Lifson JD, Burdo TH, McGrath MS, Williams K: Monocyte heterogeneity underlying phenotypic changes in monocytes according to SIV disease stage. J Leukoc Biol 2010, 87:557-567.

23. Rogacev KS, Zawada AM, Heine GH: CKD-associated atherosclerosis and monocyte heterogeneity. Kidney Int 2012, 81:599. author reply 599-600.

24. Zawada AM, Rogacev KS, Schirmer SH, Sester M, Bohm M, Fliser D, Heine $\mathrm{GH}$ : Monocyte heterogeneity in human cardiovascular disease. Immunobiology 2012, 217:1273-1284.

25. Strauss-Ayali D, Conrad SM, Mosser DM: Monocyte subpopulations and their differentiation patterns during infection. J Leukoc Biol 2007, 82:244-252.

26. Tacke F, Alvarez D, Kaplan TJ, Jakubzick C, Spanbroek R, Llodra J, Garin A, Liu J, Mack M, van Rooijen N, Lira SA, Habenicht AJ, Randolph GJ: Monocyte subsets differentially employ CCR2, CCR5, and CX3CR1 to accumulate within atherosclerotic plaques. J Clin Invest 2007, 117:185-194.

27. Tsou CL, Peters W, Si Y, Slaymaker S, Aslanian AM, Weisberg SP, Mack M, Charo IF: Critical roles for CCR2 and MCP-3 in monocyte mobilization from bone marrow and recruitment to inflammatory sites. J Clin Invest 2007, 117:902-909.

28. Si Y, Tsou CL, Croft K, Charo IF: CCR2 mediates hematopoietic stem and progenitor cell trafficking to sites of inflammation in mice. J Clin Invest 2010, 120:1192-1203.

29. Qu C, Edwards EW, Tacke F, Angeli V, Llodra J, Sanchez-Schmitz G, Garin A, Haque NS, Peters W, van Rooijen N, Sanchez-Torres C, Bromberg J, Charo IF,
Jung S, Lira SA, Randolph GJ: Role of CCR8 and other chemokine pathways in the migration of monocyte-derived dendritic cells to lymph nodes. J Exp Med 2004, 200:1231-1241.

30. Kohn LA, Hao QL, Sasidharan R, Parekh C, Ge S, Zhu Y, Mikkola HK, Crooks GM: Lymphoid priming in human bone marrow begins before expression of CD10 with upregulation of L-selectin. Nat Immuno/ 2012 13:963-971.

31. Xu H, Manivannan A, Crane I, Dawson R, Liversidge J: Critical but divergent roles for CD62L and CD44 in directing blood monocyte trafficking in vivo during inflammation. Blood 2008, 112:1166-1174.

32. Weiner LM, Li W, Holmes M, Catalano RB, Dovnarsky M, Padavic K, Alpaugh RK: Phase I trial of recombinant macrophage colony-stimulating factor and recombinant gamma-interferon: toxicity, monocytosis, and clinical effects. Cancer Res 1994, 54:4084-4090.

33. Korkosz M, Bukowska-Strakova K, Sadis S, Grodzicki T, Siedlar M: Monoclonal antibodies against macrophage colony-stimulating factor diminish the number of circulating intermediate and nonclassical (CD14(++)CD16 $(+) / C D 14(+) C D 16(++))$ monocytes in rheumatoid arthritis patient. Blood 2012, 119:5329-5330.

34. Getts DR, Terry RL, Getts MT, Muller M, Rana S, Shrestha B, Radford J, Van Rooijen N, Campbell IL, King NJ: Ly6c + "inflammatory monocytes" are microglial precursors recruited in a pathogenic manner in west Nile virus encephalitis. J Exp Med 2008, 205:2319-2337.

35. Rivollier A, He J, Kole A, Valatas V, Kelsall BL: Inflammation switches the differentiation program of Ly6Chi monocytes from antiinflammatory macrophages to inflammatory dendritic cells in the colon. J Exp Med 2012, 209:139-155.

36. Hilgendorf I, Gerhardt LM, Tan TC, Winter C, Holderried TA, Chousterman BG, Iwamoto Y, Liao R, Zirlik A, Scherer-Crosbie M, Hedrick CC, Libby P, Nahrendorf M, Weissleder R, Swirski FK: Ly-6Chigh monocytes depend on Nr4a1 to balance both inflammatory and reparative phases in the infarcted myocardium. Circ Res 2014, 114:1611-1622

37. Swirski FK, Libby P, Aikawa E, Alcaide P, Luscinskas FW, Weissleder R, Pittet MJ: Ly-6Chi monocytes dominate hypercholesterolemia-associated monocytosis and give rise to macrophages in atheromata. J Clin Invest 2007, 117:195-205.

38. Robbins CS, Hilgendorf I, Weber GF, Theurl I, Iwamoto Y, Figueiredo JL, Gorbatov R, Sukhova GK, Gerhardt LM, Smyth D, Zavitz CC, Shikatani EA, Parsons M, van Rooijen N, Lin HY, Husain M, Libby P, Nahrendorf M, Weissleder $\mathrm{R}$, Swirski FK: Local proliferation dominates lesional macrophage accumulation in atherosclerosis. Nat Med 2013, 19:1166-1172.

39. Swirski FK, Hilgendorf I, Robbins CS: From proliferation to proliferation: monocyte lineage comes full circle. Semin Immunopathol 2014, 36:137-148.

40. Libby P, Nahrendorf M, Swirski FK: Monocyte heterogeneity in cardiovascular disease. Semin Immunopathol 2013, 35:553-562.

41. Ingersoll MA, Spanbroek R, Lottaz C, Gautier EL, Frankenberger M, Hoffmann R, Lang R, Haniffa M, Collin M, Tacke F, Habenicht AJ, Ziegler-Heitbrock L, Randolph GJ: Comparison of gene expression profiles between human and mouse monocyte subsets. Blood 2010, 115:e10-e19.

42. Sunderkotter C, Nikolic T, Dillon MJ, Van Rooijen N, Stehling M, Drevets DA, Leenen PJ: Subpopulations of mouse blood monocytes differ in maturation stage and inflammatory response. J Immuno/ 2004, 172:4410-4417.

43. Landsman L, Varol C, Jung S: Distinct differentiation potential of blood monocyte subsets in the lung. J Immunol 2007, 178:2000-2007.

44. Leuschner F, Panizzi P, Chico-Calero I, Lee WW, Ueno T, Cortez-Retamozo V, Waterman P, Gorbatov R, Marinelli B, Iwamoto Y, Chudnovskiy A, Figueiredo JL, Sosnovik DE, Pittet MJ, Swirski FK, Weissleder R, Nahrendorf M: Angiotensin-converting enzyme inhibition prevents the release of monocytes from their splenic reservoir in mice with myocardial infarction. Circ Res 2010, 107:1364-1373.

45. Swirski FK, Nahrendorf M, Etzrodt M, Wildgruber M, Cortez-Retamozo V, Panizzi P, Figueiredo JL, Kohler RH, Chudnovskiy A, Waterman P, Aikawa E, Mempel TR, Libby P, Weissleder R, Pittet MJ: Identification of splenic reservoir monocytes and their deployment to inflammatory sites. Science 2009, 325:612-616.

46. Varol C, Landsman L, Fogg DK, Greenshtein L, Gildor B, Margalit R, Kalchenko V, Geissmann F, Jung S: Monocytes give rise to mucosal, but not splenic, conventional dendritic cells. J Exp Med 2007, 204:171-180.

47. Pfeffer MA, Braunwald E: Ventricular remodeling after myocardial infarction. Experimental observations and clinical implications. Circulation 1990, 81:1161-1172.

48. Tsujioka H, Imanishi T, Ikejima H, Kuroi A, Takarada S, Tanimoto T, Kitabata H, Okochi K, Arita Y, Ishibashi K, Komukai K, Kataiwa H, Nakamura N, Hirata K, 
Tanaka A, Akasaka T: Impact of heterogeneity of human peripheral blood monocyte subsets on myocardial salvage in patients with primary acute myocardial infarction. J Am Coll Cardiol 2009, 54:130-138.

49. Rogacev KS, Cremers B, Zawada AM, Seiler S, Binder N, Ege P, GrosseDunker G, Heisel I, Hornof F, Jeken J, Rebling NM, Ulrich C, Scheller B, Bohm M, Fliser D, Heine GH: CD14++CD16+ monocytes independently predict cardiovascular events: a cohort study of 951 patients referred for elective coronary angiography. J Am Coll Cardiol 2012, 60:1512-1520

50. Nahrendorf M, Swirski FK, Aikawa E, Stangenberg L, Wurdinger T, Figueiredo JL, Libby P, Weissleder R, Pittet MJ: The healing myocardium sequentially mobilizes two monocyte subsets with divergent and complementary functions. J Exp Med 2007, 204:3037-3047.

51. Saxena A, Chen W, Su Y, Rai V, Uche OU, Li N, Frangogiannis NG: IL-1 induces proinflammatory leukocyte infiltration and regulates fibroblast phenotype in the infarcted myocardium. J Immunol 2013, 191:4838-4848.

52. van der Laan AM, Hirsch A, Robbers LF, Nijveldt R, Lommerse I, Delewi R, van der Vleuten PA, Biemond BJ, Zwaginga JJ, van der Giessen WJ, Zijlstra F, van Rossum AC, Voermans C, van der Schoot CE, Piek JJ: A proinflammatory monocyte response is associated with myocardial injury and impaired functional outcome in patients with ST-segment elevation myocardial infarction: monocytes and myocardial infarction. Am Heart J 2012, 163:57-65. e2.

53. Tsujjoka H, Imanishi T, Ikejima H, Tanimoto T, Kuroi A, Kashiwagi M, Okochi K Ishibashi K, Komukai K, Ino Y, Kitabata H, Akasaka T: Post-reperfusion enhancement of CD14(+)CD16(-) monocytes and microvascular obstruction in ST-segment elevation acute myocardial infarction. Circ J 2010, 74:1175-1182.

54. Panizzi P, Swirski FK, Figueiredo JL, Waterman P, Sosnovik DE, Aikawa E, Libby P, Pittet M, Weissleder R, Nahrendorf M: Impaired infarct healing in atherosclerotic mice with Ly-6C(hi) monocytosis. J Am Coll Cardiol 2010, 55:1629-1638.

55. Tapp LD, Shantsila E, Wrigley BJ, Pamukcu B, Lip GY: The CD14++CD16+ monocyte subset and monocyte-platelet interactions in patients with ST-elevation myocardial infarction. J Thromb Haemost 2012, 10:1231-1241.

56. Urra X, Villamor N, Amaro S, Gomez-Choco M, Obach V, Oleaga L, Planas AM, Chamorro A: Monocyte subtypes predict clinical course and prognosis in human stroke. J Cereb Blood Flow Metab 2009, 29:994-1002.

57. Urra X, Cervera A, Obach V, Climent N, Planas AM, Chamorro A: Monocytes are major players in the prognosis and risk of infection after acute stroke. Stroke 2009, 40:1262-1268.

58. Kaito M, Araya S, Gondo Y, Fujita M, Minato N, Nakanishi M, Matsui M: Relevance of distinct monocyte subsets to clinical course of ischemic stroke patients. PLoS one 2013, 8:e69409.

59. Combadiere C, Potteaux S, Rodero M, Simon T, Pezard A, Esposito B, Merval R, Proudfoot A, Tedgui A, Mallat Z: Combined inhibition of CCL2, CX3CR1, and CCR5 abrogates Ly6C(hi) and Ly6C(lo) monocytosis and almost abolishes atherosclerosis in hypercholesterolemic mice. Circulation 2008, 117:1649-1657.

60. Robbins CS, Chudnovskiy A, Rauch PJ, Figueiredo JL, Iwamoto Y, Gorbatov R, Etzrodt M, Weber GF, Ueno T, van Rooijen N, Mulligan-Kehoe MJ, Libby P, Nahrendorf M, Pittet MJ, Weissleder R, Swirski FK: Extramedullary hematopoiesis generates Ly- 6 C(high) monocytes that infiltrate atherosclerotic lesions. Circulation 2012, 125:364-374.

61. Saederup N, Chan L, Lira SA, Charo IF: Fractalkine deficiency markedly reduces macrophage accumulation and atherosclerotic lesion formation in CCR2-/- mice: evidence for independent chemokine functions in atherogenesis. Circulation 2008, 117:1642-1648.

62. Rothe G, Gabriel H, Kovacs E, Klucken J, Stohr J, Kindermann W, Schmitz G: Peripheral blood mononuclear phagocyte subpopulations as cellular markers in hypercholesterolemia. Arterioscler Thromb Vasc Biol 1996, 16:1437-1447.

63. Rothe G, Herr AS, Stohr J, Abletshauser C, Weidinger G, Schmitz G: A more mature phenotype of blood mononuclear phagocytes is induced by fluvastatin treatment in hypercholesterolemic patients with coronary heart disease. Atherosclerosis 1999, 144:251-261.

64. Poitou C, Dalmas E, Renovato M, Benhamo V, Hajduch F, Abdennour M, Kahn JF, Veyrie N, Rizkalla S, Fridman WH, Sautes-Fridman C, Clement K, Cremer I: CD14dimCD16+ and CD14 + CD16+ monocytes in obesity and during weight loss: relationships with fat mass and subclinical atherosclerosis. Arterioscler Thromb Vasc Biol 2011, 31:2322-2330.

65. Jaipersad AS, Shantsila A, Lip GY and Shantsila E. Expression of monocyte subsets and angiogenic markers in relation to carotid plaque neovascularization in patients with pre-existing coronary artery disease and carotid stenosis. Annals Med 2014, 46(7):530-538. doi: 10.3109/07853890.2014.931101.
66. Zeng S, Zhou X, Ge L, Ji WJ, Shi R, Lu RY, Sun HY, Guo ZZ, Zhao JH, Jiang TM, Li YM: Monocyte subsets and monocyte-platelet aggregates in patients with unstable angina. J Thromb Thrombolysis 2014, 38:439-446.

67. Imanishi T, Ikejima H, Tsujioka H, Kuroi A, Ishibashi K, Komukai K, Tanimoto T, Ino Y, Takeshita T, Akasaka T: Association of monocyte subset counts with coronary fibrous cap thickness in patients with unstable angina pectoris. Atherosclerosis 2010, 212:628-635.

68. Coen PM, Flynn MG, Markofski MM, Pence BD, Hannemann RE: Adding exercise to rosuvastatin treatment: influence on C-reactive protein, monocyte toll-like receptor 4 expression, and inflammatory monocyte (CD14 + CD16+) population. Metab Clin Exp 2010, 59:1775-1783.

69. Rogacev KS, Zawada AM, Emrich I, Seiler S, Bohm M, Fliser D, Woollard K, Heine GH: Lower Apo a-I and lower HDL-C levels Are associated with higher intermediate CD14++CD16+ monocyte counts that predict cardiovascular events in chronic kidney disease. Arterioscler Thromb Vasc Biol 2014, 34:2120-2127.

70. Rogacev KS, Seiler S, Zawada AM, Reichart B, Herath E, Roth D, Ulrich C, Fliser D, Heine GH: CD14++CD16+ monocytes and cardiovascular outcome in patients with chronic kidney disease. Eur Heart J 2011, 32:84-92.

71. Boring L, Gosling J, Cleary M, Charo IF: Decreased lesion formation in CCR2-/- mice reveals a role for chemokines in the initiation of atherosclerosis. Nature 1998, 394:894-897.

72. Braunersreuther V, Steffens S, Arnaud C, Pelli G, Burger F, Proudfoot A, Mach F: A novel RANTES antagonist prevents progression of established atherosclerotic lesions in mice. Arterioscler Thromb Vasc Biol 2008, 28:1090-1096.

73. Braunersreuther V, Zernecke A, Arnaud C, Liehn EA, Steffens S, Shagdarsuren E, Bidzhekov K, Burger F, Pelli G, Luckow B, Mach F, Weber C: Ccr5 but not Ccr1 deficiency reduces development of diet-induced atherosclerosis in mice. Arterioscler Thromb Vasc Biol 2007, 27:373-379.

74. Ali ZA, Bursill CA, Douglas G, McNeill E, Papaspyridonos M, Tatham AL, Bendall JK, Akhtar AM, Alp NJ, Greaves DR, Channon KM: CCR2-mediated antiinflammatory effects of endothelial tetrahydrobiopterin inhibit vascular injury-induced accelerated atherosclerosis. Circulation 2008, 118:571-S77.

75. Heine GH, Ortiz A, Massy ZA, Lindholm B, Wiecek A, Martinez-Castelao A, Covic A, Goldsmith D, Suleymanlar G, London GM, Parati G, Sicari R, Zoccali C, Fliser D, European R: Cardiovascular medicine working group of the European renal association-European $\mathrm{D}$ and transplant a. Monocyte subpopul Cardiovasc Dis Nat Rev Nephrol 2012, 8:362-369.

76. Suk SH, Sacco RL, Boden-Albala B, Cheun JF, Pittman JG, Elkind MS, Paik MC, and Northern Manhattan Stroke S. Abdominal obesity and risk of ischemic stroke: The northern Manhattan stroke study. Stroke 2003, 34:1586-1592.

77. Yusuf S, Hawken S, Ounpuu S, Bautista L, Franzosi MG, Commerford P, Lang CC, Rumboldt Z, Onen CL, Lisheng L, Tanomsup S, Wangai P Jr, Razak F, Sharma AM, Anand SS, Investigators IS: Obesity and the risk of myocardial infarction in 27,000 participants from 52 countries: a case-control study. Lancet 2005, 366:1640-1649

78. Rogacev KS, Ulrich C, Blomer L, Hornof F, Oster K, Ziegelin M, Cremers B, Grenner Y, Geisel J, Schlitt A, Kohler H, Fliser D, Girndt M, Heine GH: Monocyte heterogeneity in obesity and subclinical atherosclerosis. Eur Heart J 2010, 31:369-376.

79. Cottam DR, Schaefer PA, Fahmy D, Shaftan GW, Angus LD: The effect of obesity on neutrophil Fc receptors and adhesion molecules (CD16, CD11b, CD62L). Obes Surg 2002, 12:230-235.

80. Cottam DR, Schaefer PA, Shaftan GW, Velcu L, Angus LD: Effect of surgically-induced weight loss on leukocyte indicators of chronic inflammation in morbid obesity. Obes Surg 2002, 12:335-342.

81. Murphy AJ, Akhtari M, Tolani S, Pagler T, Bijl N, Kuo CL, Wang M, Sanson M, Abramowicz S, Welch C, Bochem AE, Kuivenhoven JA, Yvan-Charvet L, Tall AR: ApoE regulates hematopoietic stem cell proliferation, monocytosis, and monocyte accumulation in atherosclerotic lesions in mice. J Clin Invest 2011, 121:4138-4149.

82. Huang LH, Gui J, Artinger E, Craig R, Berwin BL, Ernst PA, Chang CC, Chang $T Y$ : Acat1 gene ablation in mice increases hematopoietic progenitor cell proliferation in bone marrow and causes leukocytosis. Arterioscler Thromb Vasc Biol 2013, 33:2081-2087.

83. Murphy AJ, Funt S, Gorman D, Tall AR, Wang N: Pegylation of high-density lipoprotein decreases plasma clearance and enhances antiatherogenic activity. Circ Res 2013, 113:e1-e9.

84. Brown NK, Zhou Z, Zhang J, Zeng R, Wu J, Eitzman DT, Chen YE, Chang L: Perivascular adipose tissue in vascular function and disease: a review of 
current research and animal models. Arterioscler Thromb Vasc Biol 2014, 34:1621-1630.

85. Manka D, Chatterjee TK, Stoll LL, Basford JE, Konaniah ES, Srinivasan R, Bogdanov VY, Tang Y, Blomkalns AL, Hui DY, Weintraub NL: Transplanted perivascular adipose tissue accelerates injury-induced neointimal hyperplasia: role of monocyte chemoattractant protein-1. Arterioscler Thromb Vasc Biol 2014, 34:1723-1730.

86. Omar A, Chatterjee TK, Tang Y, Hui DY, Weintraub NL: Proinflammatory phenotype of perivascular adipocytes. Arterioscler Thromb Vasc Biol 2014, 34:1631-1636.

87. Owen MK, Noblet JN, Sassoon DJ, Conteh AM, Goodwill AG, Tune JD: Perivascular adipose tissue and coronary vascular disease. Arterioscler Thromb Vasc Biol 2014, 34:1643-1649.

88. Withers SB, Bussey CE, Saxton SN, Melrose HM, Watkins AE, Heagerty AM: Mechanisms of adiponectin-associated perivascular function in vascular disease. Arterioscler Thromb Vasc Biol 2014, 34:1637-1642

89. Henrichot E, Juge-Aubry CE, Pernin A, Pache JC, Velebit V, Dayer JM, Meda $P$, Chizzolini C, Meier CA: Production of chemokines by perivascular adipose tissue: a role in the pathogenesis of atherosclerosis? Arterioscler Thromb Vasc Biol 2005, 25:2594-2599.

90. Jabs A, Okamoto E, Vinten-Johansen J, Bauriedel G, Wilcox JN: Sequentia patterns of chemokine- and chemokine receptor-synthesis following vessel wall injury in porcine coronary arteries. Atherosclerosis 2007, 192:75-84.

91. Alonso A, Lopez FL, Matsushita K, Loehr LR, Agarwal SK, Chen LY, Soliman EZ, Astor BC, Coresh J: Chronic kidney disease is associated with the incidence of atrial fibrillation: the atherosclerosis risk in communities (ARIC) study. Circulation 2011, 123:2946-2953.

92. Drueke TB, Massy ZA: Atherosclerosis in CKD: differences from the general population. Nat Rev Nephrol 2010, 6:723-735.

93. Heine GH, Ulrich C, Seibert E, Seiler S, Marell J, Reichart B, Krause M, Schlitt A, Kohler H, Girndt M: CD14(++)CD16+ monocytes but not total monocyte numbers predict cardiovascular events in dialysis patients. Kidney Int 2008, 73:622-629.

94. Ulrich C, Heine GH, Seibert E, Fliser D, Girndt M: Circulating monocyte subpopulations with high expression of angiotensin-converting enzyme predict mortality in patients with end-stage renal disease. Nephrol Dial Transplant 2010, 25:2265-2272.

95. Ulrich C, Heine GH, Gerhart MK, Kohler H, Girndt M: Proinflammatory CD14 + CD16+ monocytes are associated with subclinical atherosclerosis in renal transplant patients. Am J Transplant 2008, 8:103-110.

96. Rogacev KS, Ziegelin M, Ulrich C, Seiler S, Girndt M, Fliser D, Heine GH: Haemodialysis-induced transient CD16+ monocytopenia and cardiovascular outcome. Nephrol Dial Transplant 2009, 24:3480-3486.

97. Ghigliotti G, Barisione C, Garibaldi S, Brunelli C, Palmieri D, Spinella G, Pane B, Spallarossa P, Altieri P, Fabbi P, Sambuceti G, Palombo D: CD16(+) monocyte subsets are increased in large abdominal aortic aneurysms and are differentially related with circulating and cell-associated biochemical and inflammatory biomarkers. Dis Markers 2013, 34:131-142.

98. Tsubakimoto Y, Yamada H, Yokoi H, Kishida S, Takata H, Kawahito H, Matsui A, Urao N, Nozawa Y, Hirai H, Imanishi J, Ashihara E, Maekawa T, Takahashi T, Okigaki M, Matsubara $\mathrm{H}$ : Bone marrow angiotensin AT1 receptor regulates differentiation of monocyte lineage progenitors from hematopoietic stem cells. Arterioscler Thromb Vasc Biol 2009, 29:1529-1536.

99. Vuk-Pavlovic Z, Kreofsky TJ, Rohrbach MS: Characteristics of monocyte angiotensin-converting enzyme (ACE) induction by dexamethasone. J Leukoc Biol 1989, 45:503-509.

100. Merino A, Alvarez-Lara MA, Ramirez R, Carracedo J, Martin-Malo A, Aljama P: Losartan prevents the development of the pro-inflammatory monocytes CD14 + CD16+ in haemodialysis patients. Nephrol Dial Transplant 2012, 27:2907-2912

101. Baeten D, Boots AM, Steenbakkers PG, Elewaut D, Bos E, Verheijden GF, Berheijden G, Miltenburg AM, Rijnders AW, Veys EM, De Keyser F: Human cartilage gp-39+, CD16+ monocytes in peripheral blood and synovium: correlation with joint destruction in rheumatoid arthritis. Arthritis Rheum 2000, 43:1233-1243.

102. Iwahashi M, Yamamura M, Aita T, Okamoto A, Ueno A, Ogawa N, Akashi S, Miyake K, Godowski PJ, Makino H: Expression of Toll-like receptor 2 on CD16+ blood monocytes and synovial tissue macrophages in rheumatoid arthritis. Arthritis Rheum 2004, 50:1457-1467.
103. Benucci M, Saviola G, Baiardi P, Manfredi M, Sarzi Puttini P, Atzeni F: Determinants of risk infection during therapy with anti TNF-alpha blocking agents in rheumatoid arthritis. Rheumatol J 2012, 6:33-37.

104. Abeles RD, McPhail MJ, Sowter D, Antoniades CG, Vergis N, Vijay GK, Xystrakis E, Khamri W, Shawcross DL, Ma Y, Wendon JA, Vergani D: CD14, CD16 and HLA-DR reliably identifies human monocytes and their subsets in the context of pathologically reduced HLA-DR expression by CD14(hi) /CD16(neg) monocytes: expansion of CD14(hi) /CD16(pos) and contraction of CD14(lo) /CD16(pos) monocytes in acute liver failure. J Int Soc Anal Cytol 2012, 81:823-834.

105. Cooper DL, Martin SG, Robinson Jl, Mackie SL, Charles CJ, Nam J, Consortium Y, Isaacs JD, Emery P, Morgan AW: FcgammaRIlla expression on monocytes in rheumatoid arthritis: role in immune-complex stimulated TNF production and non-response to methotrexate therapy. PLOS ONE 2012, 7:e28918.

106. Hanai H, lida T, Takeuchi K, Watanabe F, Yamada M, Kikuyama M, Maruyama Y, Iwaoka Y, Hirayama K, Nagata S, Takai K: Adsorptive depletion of elevated proinflammatory CD14 + CD16 + DR++ monocytes in patients with inflammatory bowel disease. Am J Gastroenterol 2008, 103:1210-1216.

107. Koch S, Kucharzik T, Heidemann J, Nusrat A, Luegering A: Investigating the role of proinflammatory $C D 16+$ monocytes in the pathogenesis of inflammatory bowel disease. Clin Exp Immunol 2010, 161:332-341.

108. Banks C, Bateman A, Payne R, Johnson P, Sheron N: Chemokine expression in IBD. Mucosal chemokine expression is unselectively increased in both ulcerative colitis and Crohn's disease. J Pathol 2003, 199:28-35.

109. Nishimura M, Kuboi Y, Muramoto K, Kawano T, Imai T: Chemokines as novel therapeutic targets for inflammatory bowel disease. Ann N Y Acad Sci 2009, 1173:350-356.

110. Thiesen S, Janciauskiene S, Uronen-Hansson H, Agace W, Hogerkorp CM, Spee P, Hakansson K, Grip O: CD14(hi)HLA-DR(dim) macrophages, with a resemblance to classical blood monocytes, dominate inflamed mucosa in Crohn's disease. J Leukoc Biol 2014, 95:531-541.

111. Chiu YG, Shao T, Feng C, Mensah KA, Thullen M, Schwarz EM, Ritchlin CT: CD16 (FcRgammalll) as a potential marker of osteoclast precursors in psoriatic arthritis. Arthritis Res Therapy 2010, 12:R14.

112. Appleby $\sqcup$, Nausch N, Midzi N, Mduluza T, Allen JE, Mutapi F: Sources of heterogeneity in human monocyte subsets. Immunol Lett 2013, 152:32-41.

\section{Submit your manuscript to a SpringerOpen ${ }^{\odot}$ journal and benefit from:}

- Convenient online submission

- Rigorous peer review

- Immediate publication on acceptance

- Open access: articles freely available online

- High visibility within the field

- Retaining the copyright to your article

Submit your next manuscript at springeropen.com 